\title{
Mesoporous Silica MCM-41 as a Carriers Material for Nystatine Drug in Delivery System
}

\author{
Talib M. Albayati* \\ Ali M. AlKafajy** \\ *** Department of Chemical Engineering/ University of Technology/ Baghdad /Iraq \\ *Email:talib_albyati@yahoo.com \\ **Email: alkafagae1986@yahoo.com
}

(Received 7 October 2018; accepted 4 November 2018)

https://doi.org/10.22153/kej.2019.11.003

\begin{abstract}
In the present study, MCM-41 was synthesis as a carrier for poorly drugs soluble in water, by the sol-gel technique. Textural and chemical characterizations of MCM-41 were carried out by X-ray diffraction (XRD), Fourier transform infrared (FTIR), scanning electron microscope (SEM), and thermal gravimetric analysis (TGA). The experimental results were analyzed mesoporous carriers MCM-41. With maximum drug loading efficiency in MCM-41 determined to be $90.74 \%$. The NYS released was prudently studied in simulated body fluid (SBF) pH 7.4 and the results proved that the release of NYS from MCM-41 was (87.79\%) after $18 \mathrm{hr}$. The data of NYS released was found to be submitted a Weibull model with a correlation coefficient of (0.995). The Historical data experimental design facilitated the formulation and optimization of sustained discover the optimal formulation to loading drug, combine process variables, mixture components and categorical factors in one design.
\end{abstract}

Keywords: MCM-41 silica, Nystatine, adsorption, drug delivery, release systems.

\section{Introduction}

Oral delivery is the favored route of medication management, but is often hampered by some challenges such as inadequate physical, biopharmaceuticals, many existing pharmaceuticals suffer from poor water solubility and/or physiological properties, resulting in inadequate solubility and bioavailability by oral [1-2]. During the past decades, porous silica has been used with many attractive properties widely in biomedical applications and drug delivery scale materials for effective oral delivery of poorly soluble drugs [3]. In addition to widely studied organic and inorganic polymers,micro-and nanoporous material have attracted considerable attention recently because they are widely used as controlled delivery systems for controlled drugs and lowering the drug concentrations to be transported by employing nanostructure based on drug delivery vehicles with enhanced adsorption capability and controlled drug release properties can improve the drug's efficiency [4-5]. The applications of mesoporous silica nanoparticles (MSNs) in pharmaceuticals are increasing day by day and are receiving careful attention (Since the discovery of mesoporous silica materials in the 1990s, the synthesis and applications of (MSNs) have received substantial attention because their highly porosity, high surface area, tunable pores, non-cytotoxic properties, and well-ordered structure, well-defined surface properties and high loading and easy control of release, mesoporous materials seem ideal carrier's drugs[6]. The mesoporous has a uniform and adjustable pore size of (2-50) nm, In covenant with (IUPAC) "the International Union of Pure and Applied Chemistry commendation"[7]. Among these mesoporous silica "Mobil Composition of Matter number 41 (MCM-41)" that pore diameter $(2 \mathrm{~nm}$ $<\mathrm{d}_{\mathrm{ap}}<6 \mathrm{~nm}$ ) [8] and "Santa Barbara Amorphous number 15 (SBA-15)" with pore diameter $(4 \mathrm{~nm}<$ 
$\mathrm{d}_{\mathrm{ap}}<13 \mathrm{~nm}$ ) [9] with a two-dimensional hexagonal arrangement of cylindrical pores of a uniform size are amongst the most common investigated mesoporous materials. MCM-41 is a widely researched type of MSNs for drug delivery [1011]. MCM-41, it has unidirectional and very uniform channel structures from Medium hexagonal pores with pore size distributions are very narrow with cylindrical ordered hexagonal mesopores structure, was firstly synthesized in a highly acidic media using amphiphilic tri-block co-polymer of "Cetyl-Trimethyl-AmmoniumBromide (CTAB)" as template in 1992 [9-12]. The loading and releasing of drugs by the (MSNs) is dependent on factors such as the surface chemical nature, size of pore, specific surface area and morphology of mesoporous silica [13-14].

Experimental design has been used for several decades in science that provides specific information experiments, The factors really influencing was determined and see whether the effects of certain factors depend on other factors. The effect factors were taking into account possible interaction between factors. Use this program to help optimize process, achieve optimal performance, discover the optimal formulation, combine process variables, mixture components and categorical factors in one design. The two parameters that studied (concentration and time) and the response was insert as group and decide the optimal parameter theoretical and experimental and studied the more effect parameter [15].

In this work preparation and characterization of MCM-41 and used for the loading of Nystatine (NYS), and select the best operating conditions for the different studied parameters of loading (concentration of drug and contact time) and the release of (NYS) in simulated body fluid (SBF) $\mathrm{pH}$ 7.4. Nystatin (NYS) chemically "tetraene diene polyene macrolide" $\left(\mathrm{C}_{47} \mathrm{H}_{75} \mathrm{NO}_{17}\right)$ shown in Fig.1. It's possesses different hydrophilic and lipophilic moieties: the hydrophilic area is composed of alcohols, carboxylic acid, and sugar whereas the lipophilic one consists of a chromophore of six conjugated double bonds [16]. Nystatin (NYS) is commonly employed to treat fungal infections in HIV-infected, it's used orally, but a disadvantage of these formulations is the limited residence time of it's in the affected areas [17]. The dosage form needs to reside at the site of infection for a prolonged period. These limitations can be overcome by a drug delivery system because of portability, convenient application, long retention time, easy storage and handling and improved stability [18].

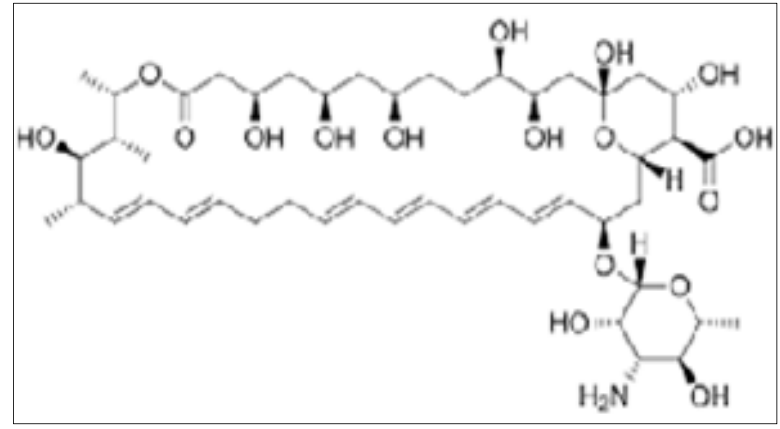

Fig. 1. The 2D structure of NYS.

\section{Experimental \\ 2.1 Chemicals}

Nystatine was purchased from Al KINDI Company for Pharmaceutical Industries in Iraq. Cetyl Trimethy Ammonium Bromide $\mathrm{CH}_{3}\left(\mathrm{CH}_{2}\right)_{15} \mathrm{~N}(\mathrm{Br})\left(\mathrm{CH}_{3}\right)_{3}$, (CTAB, 99\%) with Mwt. $\quad 364.45 \mathrm{~g} / \mathrm{mol}$ and Tetra-Ethyl-OrthoSilicate (TEOS, 98\%) were obtained from Sigma Chemicals. Hydrochloric acid, potassium dihydrogen phosphate $\left(\mathrm{KH}_{2} \mathrm{PO}_{4}, 99.5 \%\right.$, Mwt 136.2) and potassium hydrogen phosphate $\left(\mathrm{K}_{2} \mathrm{HPO}_{4}, 98 \%\right.$, Mwt 178.3) were purchased from $\mathrm{CDH}$ India.

\subsection{Preparation of Mesoporous MCM-41}

The mesoporous MCM-41 was purely synthesized according to the literature using $\mathrm{SiO}_{2}$ under basic conditions and CTAB, Aldrich as a structural directing agent [9-12] and (TEOS) was used as silica precursor. First, prepare a mixture containing $\mathrm{NaOH}$ with a weight of $0.35 \mathrm{~g}$ and 30 $\mathrm{mL}$ of distillate water, dissolve $1.01 \mathrm{~g}$ of CTAB in solution. Then, added $5.78 \mathrm{~g}$ of TOES to the mixture drop by drop, under $1 \mathrm{~h}$ of stirring at room ambient temperature. The homogeneous mixture output was crystallized under constant hydrothermal temperature $\left(110^{\circ} \mathrm{C}\right)$ in the 96 hour in in autoclave device. The solid product obtained by filtration was washed using distill water to remove the micro-surface agent. The solid material obtained at $40{ }^{\circ} \mathrm{C}$ was then dried overnight and the calcination was performed at $550^{\circ} \mathrm{C}$ for 6 hours to remove the surface agent, mold, and MCM-41 was obtained as show in Fig. 2. [20]. 


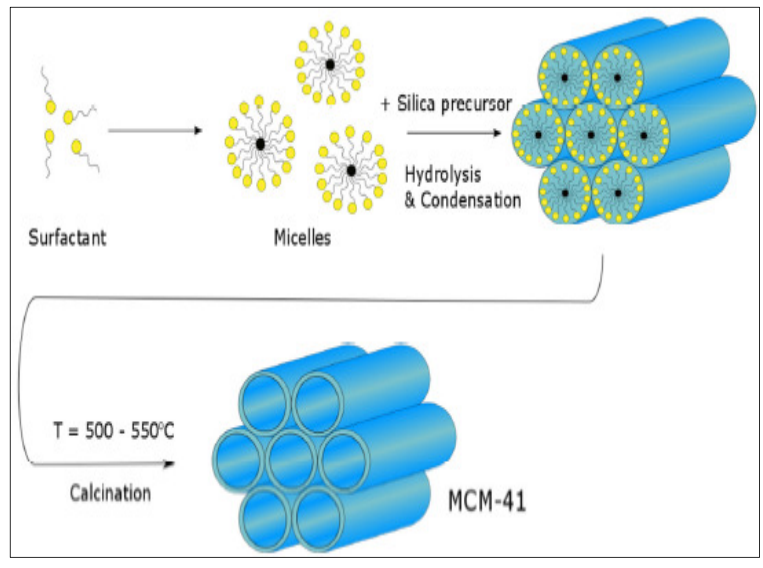

Fig. 2. Scheme of synthesis the MCM-41.

\subsection{Characterization}

The X-ray diffraction patterns for the mesoporous sample were used to show the crystalline structure and collected using an x-ray diffractometer (Type: Shimadzu-6000, Origin: Japan) with a $\mathrm{Cu} \mathrm{K \alpha}$ radiation $(\lambda 1.154 \mathrm{~A})$, with $2 \theta$ in the range $0^{\circ}$ to $10^{\circ}$ with scan rate $2(\mathrm{deg} / \mathrm{min})$. The unit cell and $\mathrm{d}$-spacing factors were obtained by using the equations $\mathrm{n} \lambda=2 \mathrm{~d} \sin \theta$ and $\mathrm{ao}=2 \mathrm{~d}_{100} / \sqrt{3}$. The SEM analysis (Scanning Electron Microscopy) show the morphology of MCM-41 was performed using SEM instrument [Type: VEGA 3 LM, Origin: Germany]. The FTIR instrument was used to analyze the chemical bonds of MCM-41. The scanning range was 400$4000 \mathrm{~cm}^{-1}$ and the resolution was $4 \mathrm{~cm}^{-1}$ and the analysis was carried out using FT-IR [Type: Bruker -Tensor 27, Origin: Germany]. Thermogravimetric analysis (TGA) for MCM-41 and NYS@MCM-41 was performed using thermogravimetric analyzer [Type: STA PT1000, origin: USA], the sample was heated from room temperature to $600{ }^{\circ} \mathrm{C}$ with rate of heating $10^{\circ} \mathrm{C}$ $\mathrm{min}^{-1}$ to obtain information concerning thermal stability.

\subsection{Nystatine Loading}

The loading experiment was conducted by contacting $50 \mathrm{~mL}$ of known concentration of NYS with a $0.14 \mathrm{~g}$ of MCM-41 in $50 \mathrm{~mL}$ of conical flasks which were closed and placed in a shaker at the constant agitation speed at room temperature. The amount of NYS loaded was calculated using the absorbance values obtained at $305 \mathrm{~nm}$. The NYS drug loading was estimated according to the Eq.1 [21].
Drug loading $\%=\frac{\mathrm{M} 2-\mathrm{M} 1}{M 3} * 100 \%$

\subsection{Nystatine Release}

The release of the NYS from MCM-41 have done in laboratory equipment at given time intervals. The suspension was withdrawn by syringe into a quartz cuvette. The UV-Vis spectrophotometer was used to measure the amount of the released drugs NYS at $305 \mathrm{~nm}$, according to Equation (2)[22].

$\%$ Release $=\frac{\text { Weight of Drug in solution }}{\text { Weight of Drug in MSMs }} * 100 \%$

\subsection{Experimental Design}

Response surface methodology (RSM) is a statistical method used for experiment design and optimization where experimental responses are fitted with quadratic functions. The objective function of the current study was chosen to maximize the drug loading (DL\%) though minimizing the dose of mesoporous carriers and concentration of drugs. Historical data design was used to statistically optimize the formulation parameter and estimate the chief parameters effects, interactions effect and quadratic effect of the formulations ingredient on the \% drug loading a nano- carrier systems [23].

\section{Results and Discussion 3.1 X-Ray Diffraction Pattern}

The different supports were characterized by standard technique. The X-ray patterns of the solid MCM-41 as produced. Fig. (3) shows the presence of reflections at $2 \theta^{\circ}$ angle of $2.86^{\circ}, 4.4^{\circ}$ and $5^{\circ}$, corresponding to planes (100), (110) and (200), reflections related through p6 mm hexagonal symmetry characteristic for MCM-41 material [24]. The position of the first peak, $(10$ 0 ) that presented in Fig. (3) allows direct determination of the center-center distance (The lattice parameters) between adjacent tubes using $\mathrm{a}_{0}=\left(2 * \mathrm{~d}_{100} / \sqrt{3}\right)$ [25]. The calculated $\mathrm{d}_{100}$ and $\mathrm{a}_{\mathrm{o}}$ values are given in Table (1). 


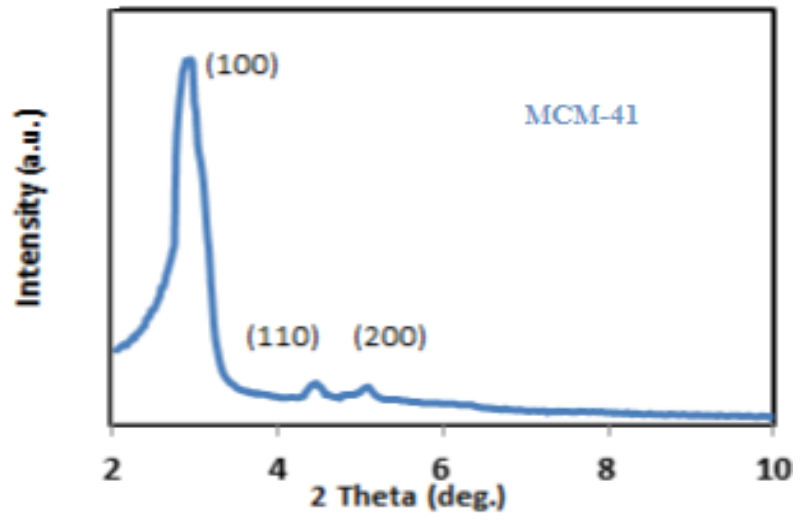

Fig. 3. XRD pattern for MCM-41.

\subsection{Scanning Electron Microscopy (SEM)}

The morphology of mesoporous materials was analyzed by SEM. Fig. (4) shows image of MCM41. The SEM image obviously presented that MCM-41, indicate the presences of agglomerate sphere particles shapes and taking smooth surfaces. [26].

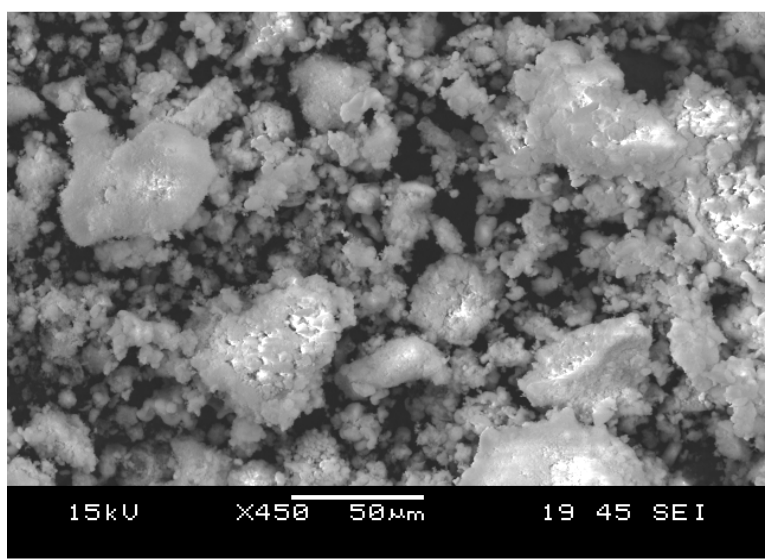

Fig. 4. Typical SEM image for MCM-41.

\subsection{FT.IR Spectra}

Fig. 5 shows FT-IR spectra of MCM-41. A broad band around $3442-3440 \mathrm{~cm}^{-1}$ is given to the stretching type vibration of surface silanol group ( $\mathrm{Si}-\mathrm{O}-\mathrm{H})$ for MCM-41, which is associated with bending at a range 1687 and $1630 \mathrm{~cm}^{-1}$ and stretching type vibration of $(\mathrm{H}-\mathrm{O}-\mathrm{H})$ hydrogen bonded water adsorbed on the surface for SBA15. Characteristic mesoporous silica $\mathrm{Si}-\mathrm{O}-\mathrm{Si}$ stretching mode vibration is observed at 1336 $\mathrm{cm}^{-1}$ and $1084 \mathrm{~cm}^{-1}$ for MCM-41, which are assigned to symmetric and asymmetric stretching mode respectively. Another peak at $467 \mathrm{~cm}^{-1}$ is the $\mathrm{Si}-\mathrm{O}-\mathrm{Si}$ bending type vibration [25].

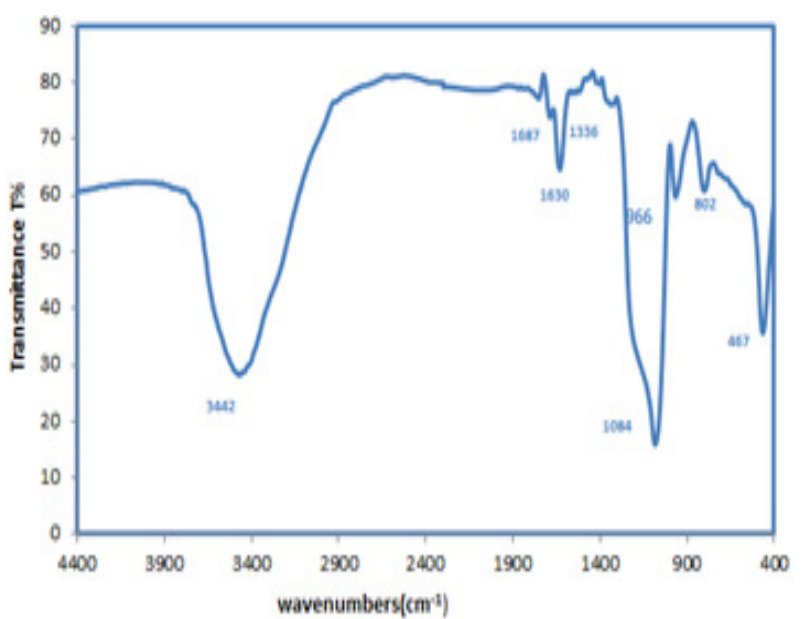

Fig. 5. FT-IR spectra of MCM-41.

\subsection{Thermal Gravimetric Analyses (TGA)}

TGA measures the losses in mass that is related to the total drug content in the sample. The TGA curves for MCM-41, NYS@MCM-41 are shown in Fig.6. Samples are heating to $600{ }^{\circ} \mathrm{C}$, at heating rate of $10{ }^{\circ} \mathrm{C} / \mathrm{min}$. The thermal gravimetric curves presented weight loss of NYS loading by MCM-41 (9.52\%) and no weight loses of pure MCM-41.

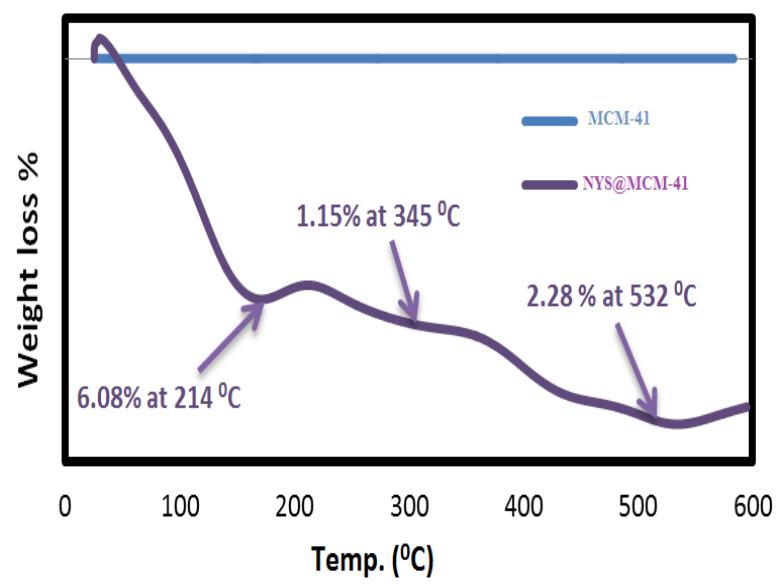

Fig. 6. Thermal gravimetric analysis for MCM-41 \& NYS@MCM-41.

\subsection{Response Surface Analysis for NYS Drug}

Figs. 7 shows the effects of two factors in response (DL\%), the effact of time and concentration in drug loading (DL\%), when the $\mathrm{pH}=2$ and dose. $=0.14 \mathrm{gm}$, observed that at intermediate concentration of NYS drug at 
$30 \mathrm{mg} / \mathrm{l}$, the drug loading efficiency of mesoporous increases when contact time at 24 $h$ and at high concentration of NYS drug stemmed in the formation of aggregate rather than mesoporous, which is extremely undesire so, the maximum DL\% show in time $=24 \mathrm{~h}$, conce. $=30 \mathrm{mg} / 1, \mathrm{pH}=2$ and dose. $=0.14 \mathrm{gm}$.

Table 1,

The properties of MCM-41 Structure.

\begin{tabular}{lllllll}
\hline Mesoporous & $\mathbf{d}_{\mathbf{1 0 0}}(\mathbf{n m})$ & $\mathbf{a}_{\mathbf{0}}(\mathbf{n m})$ & $\mathbf{D}_{\mathbf{p}}(\mathbf{n m})$ & $\mathbf{W t}(\mathbf{n m})$ & $\mathbf{V p}(\mathbf{c m} / \mathbf{g})$ & $\mathbf{S}_{\mathbf{B E T}}\left(\mathbf{m}^{\mathbf{2}} / \mathbf{g}\right)$ \\
\hline MCM-41 & 3.34 & 3.861 & 2.32 & 1.541 & 0.69 & 1394 \\
\hline
\end{tabular}

- d-Spacing of (100) reflection. Unit cell constant, $\mathrm{a}_{0}=2 \mathrm{~d} 100 / \sqrt{3}$. The thickness of the pore wall calculated by the difference (ao Dp). At $\mathrm{p} / \mathrm{p}_{0}=0.982$ of $\mathrm{N}_{2}$ volume adsorbed the total pore volume was taken.
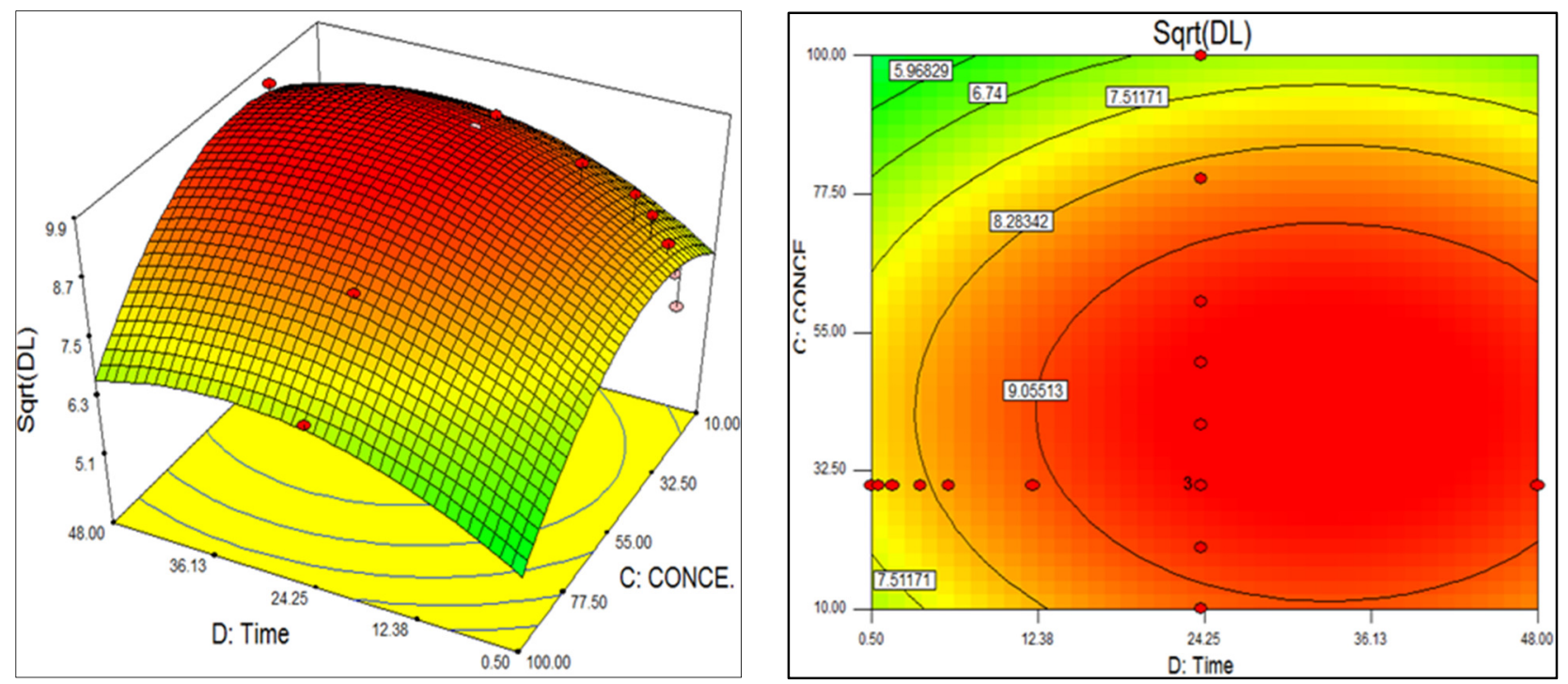

Fig. 7. 3D surface plot \& 2D contour plot for effect of Time and Conce. on DL\%.

\subsection{Nystatine Loading}

\subsubsection{Effect of Initial Drug Concentration}

The effect of initial NYS concentration was studied by changing concentration from $10 \mathrm{mg} / \mathrm{L}$ to $100 \mathrm{mg} / \mathrm{L}$ as shown in Fig.8

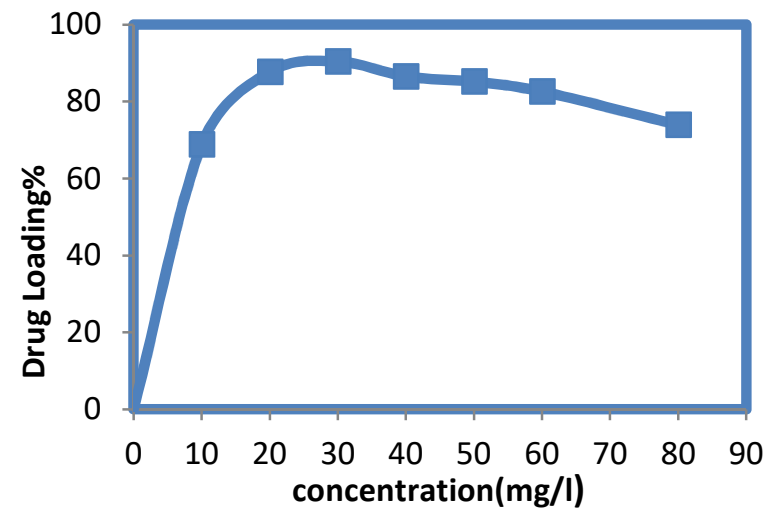

Fig. 8. Effect of the initial NYS concentration on the $\mathrm{DL} \%$ at: $(\mathrm{pH}=2$, dosage $=0.14 \mathrm{~g} / 50 \mathrm{ml}$, contact time $=24 h$ ).
Drug loading efficiency (DL\%) decreased with increasing concentration of NYS drug from $30 \mathrm{mg} / \mathrm{l}$ to $80 \mathrm{mg} / \mathrm{L}$. The higher (DL\%) were $90.47 \%$ at $30 \mathrm{mg} / \mathrm{L}$, the lower (DL\%) are $73.98 \%$ at concentration drug $80 \mathrm{mg} / \mathrm{l}$. The decrease of the drug loading of NYS was due to, the MCM-41 had limited number of active sites which have become saturated above a certain concentration. Conversely, in the case of a lower concentration of NYS that more mesoporous sites were available for NYS molecules, this is agreement with Shah \& Rajput (2017) [27].

\subsubsection{Effect of Contact Time}

The effect of contact time for loading NYS drug by the mesoporous MCM- 41 at $\mathrm{C}_{0}=30$ $\mathrm{mg} / \mathrm{L}, \mathrm{pH}=2$ and dose $=0.14 \mathrm{~g}$ is shown in Fig. 9. The rate of the drug loading is rapid in the first $30 \mathrm{~min}(48.64 \%)$ and, thereafter, the loading increased gradually and the it's reached equilibrium at $24 \mathrm{hr}(90.74 \%)$. Large numbers of 
devoid surface sites are obtainable for drug sorption through the initial stages, and after a period of time, the residual devoid surface sites are hard to be occupied because repulsive forces among the solute molecules on the solid and bulk phases [28], so we noted after $48 \mathrm{hr}$ the drug loading decrease to $89.11 \%$.

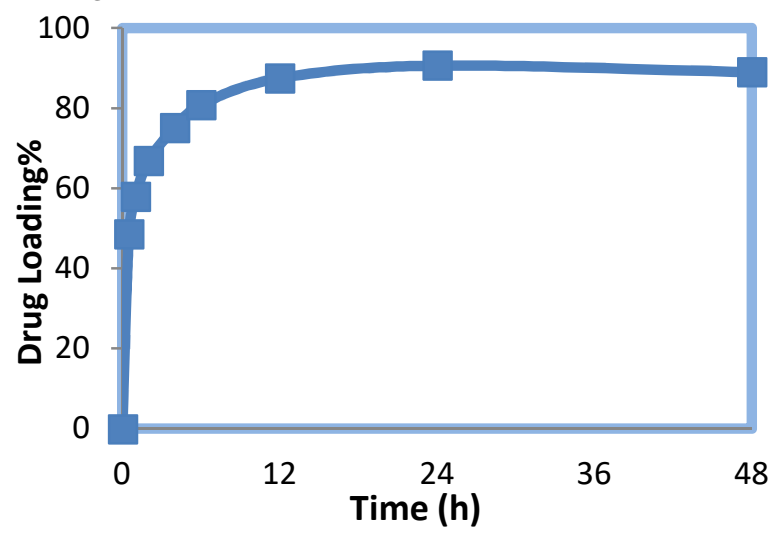

Fig. 9. Effect contact time on the drug loading at: $(\mathrm{pH}=2$, dosage $=0.14 \mathrm{~g} / 50 \mathrm{ml}$, conce. of drug=30 $\mathrm{mg} / \mathbf{l})$.

\subsection{Nystatine Release}

The in vitro release of NYS from MCM-41 mesoporous was carried out at $\mathrm{pH} 7.4$ (the physiological $\mathrm{pH}$ in the human blood is around 7.4), and showed drug release behaviour Fig. 10. At pH 7.4 and body temperature $\left(37^{\circ} \mathrm{C}\right)$, An UV vis spectrometer at $305 \mathrm{~nm}$, was used to measure the NYS release, after the initial release of NYS is about $20 \%$ in first hour when the concentration gradient between surfaces of the MCM-41 in the bulk media ( $\mathrm{SBF}, \mathrm{pH}=7.4, \mathrm{~T}=37^{\circ} \mathrm{C}$ ) was large, leading to large percent of NYS released, the drug release rate was relatively slow and was further reduced after $18 \mathrm{~h}$ (equilibrium was reached). The cumulated release amount about $87.97 \%$ after 18 $\mathrm{h}$ and mechanism of the electrostatic repulsion, as experiential in MCM-41 mesoporous silica in which silanol group are deprotonate in $\mathrm{pH} 7.4$ forcing the loading drug to be released and this phenomenon can be explained as follows the PBS is a negative charge inducer and have negatively zeta potential charge. So, it's possible to interaction with positively charged of NYS drug. [29-30].

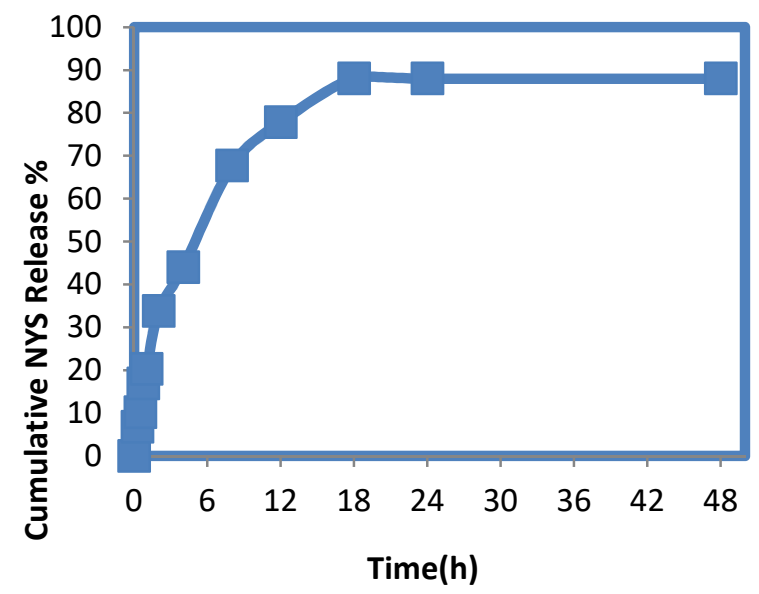

Fig.10. Release of NYS from MCM-41 in SBF at: (pH =7.4, $\left.\mathbf{T}=37^{\circ} \mathrm{C}\right)$.

\section{8 kinetic Release of Nystatine}

The kinetic of drug release on MCM-41 was studied by using First order, Higuchi, KorsmeyerPeppas, and Weibull kinetics models, by Eq. (3, 4, 5 and 6).

First order

$\log (100-W)=\log 100-K 1 t$

Higuchi

$\mathrm{Q}=\mathrm{K}_{\mathrm{H}} \mathrm{t}^{1 / 2}$

Korsmeyer-Peppas

$\frac{\mathrm{Mt}}{M \infty}=\mathrm{Kt}^{\mathrm{n}}$

Weibull kinetics models

$\log \left[\operatorname{Ln}\left(\frac{1}{1-\mathrm{f}}\right)\right]=\operatorname{mLog} \mathrm{t}-\operatorname{Ln} \mathrm{t}_{0}$

It's used to estimate the mechanism of the drug release. The obtained results from the linearized of models for release of drugs (constants \& correlation coefficient) are listed in Table 2.

Table 2,

Release kinetic parameters of drugs in SBF ( $\mathrm{pH}=7.4$ )

\begin{tabular}{|c|c|c|c|c|c|c|c|c|c|}
\hline \multirow{2}{*}{ Drug } & \multicolumn{2}{|c|}{ First order } & \multicolumn{2}{|r|}{ Higuchi } & \multicolumn{3}{|c|}{ Korsmeyer-peppos } & \multicolumn{2}{|c|}{ Weibull } \\
\hline & $\mathbf{R}^{2}$ & $K_{1}\left(h^{-1}\right)$ & $\mathbf{R}^{2}$ & $K_{H}\left(\% h^{1 / 2}\right)$ & $\mathbf{R}^{2}$ & n & $K\left(h^{-n}\right)$ & $\mathbf{R}^{2}$ & $\mathbf{m}$ \\
\hline NYS@MCM-41 & 0.993 & 0.049 & 0.983 & 21.87 & 0.978 & 0.6089 & 17.9 & 0.995 & 0.796 \\
\hline
\end{tabular}



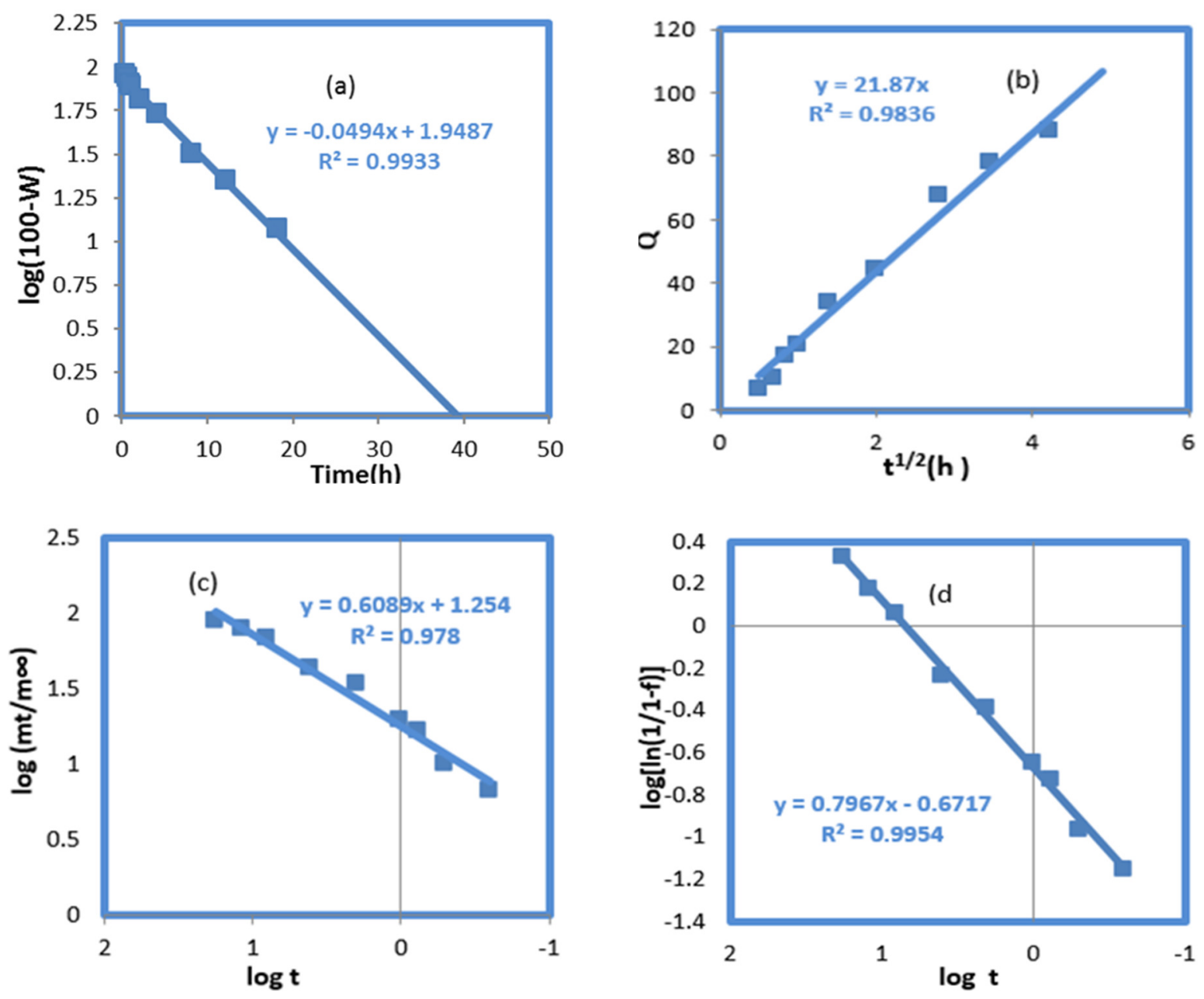

Fig. 11. Kinetic release of NYS for (a) first order, (b) Higuchi model, (c) Korsmeyers Peppas, and (d) Weibull models.

\section{Conclusions}

Mesoporous silica MCM-41 with high surface area was synthesis by sol-gel technic and used as naocarrier in drug delivery system. NYS was loading by MCM-41 and the maximum loading percentage was $90.74 \%$. The NYS release was studied at SBF media with $\mathrm{pH}$ (7.4). The time of NYS release was $(87.79 \%)$ after $18 \mathrm{hr}$. The kinetics of release of NYS drug from MCM-41 is fully fit by a weibull model with a correlation coefficient of (0.995).

\section{Abbreviations}

BET Brunauer - Emmett - Teller

CTAB CetylTrimethyl Ammonium Bromide $\mathrm{D}_{\mathrm{p}} \quad$ Pore Diameter

IUPAC International Pure and Applied Chemistry

MCM Mobil Composition of Matter
MSNs Mesoporous Silica Nanoparticles

NYS Nystatine

RSM Response surface methodology

SBA Santa Barbara Amorphous

SBF Simulated Body Fluid

TEOS TetraEthyl OrthoSilicate

\section{References}

[1]Varma, M. V., Khandavilli, S., Ashokraj, Y., Jain, A., Dhanikula, A., Sood, A., ... \& Agrawal, S. (2004). Biopharmaceutic classification system: a scientific framework for pharmacokinetic optimization in drug research. Current drug metabolism, 5(5), 375388.

[2]Lipinski, C. A. L. F. (2002). Poor aqueous solubility-an industry wide problem in drug discovery. Am Pharm Rev, 5(3), 82-85.

[3]Mei, L., Zhang, Z., Zhao, L., Huang, L., Yang, X. L., Tang, J., \& Feng, S. S. (2013). 
Pharmaceutical nanotechnology for oral delivery of anticancer drugs. Advanced drug delivery reviews, 65(6), 880-890.

[4]Shahadat, M., Teng, T. T., Rafatullah, M., \& Arshad, M. (2015). Titanium-based nanocomposite materials: a review of recent advances and perspectives. Colloids and Surfaces B: Biointerfaces, 126, 121-137.

[5]Kolhe, P., Misra, E., Kannan, R. M., Kannan, S., \& Lieh-Lai, M. (2003). Drug complexation, in vitro release and cellular entry of dendrimers and hyperbranched polymers. International journal of pharmaceutics, 259(1-2), 143-160.

[6]Safari, J., \& Zarnegar, Z. (2014). Advanced drug delivery systems: Nanotechnology of health design A review. Journal of Saudi Chemical Society, 18(2), 85-99.

[7]Burness, L. T. (2009). Mesoporous materials: properties, preparation and applications. Nova Science Publishers.

[8]Beck, J. S., Vartuli, J. C., Roth, W. J., Leonowicz, M. E., Kresge, C. T., Schmitt, K. D., ... \& Higgins, J. B. (1992). A new family of mesoporous molecular sieves prepared with liquid crystal templates. Journal of the American Chemical Society, 114(27), 1083410843.

[9]Zhao, D., Huo, Q., Feng, J., Chmelka, B. F., \& Stucky, G. D. (1998). Nonionic triblock and star diblock copolymer and oligomeric surfactant syntheses of highly ordered, hydrothermally stable, mesoporous silica structures. Journal of the American Chemical Society, 120(24), 6024-6036.

[10] Fu, T., Lu, J., Guo, L., Zhang, L., Cai, X., \& Zhu, H. (2012). Improving bioavailability of silybin by inclusion into SBA-15 mesoporous silica materials. Journal of nanoscience and nanotechnology, 12(5), 3997-4006.

[11] Wang, Z., Chen, B., Quan, G., Li, F., Wu, Q., Dian, L., ... \& Wu, C. (2012). Increasing the oral bioavailability of poorly water-soluble carbamazepine using immediate-release pellets supported on SBA-15 mesoporous silica. International journal of nanomedicine, 7, 5807.

[12] Majeed, N. S., \& Saleh, A. A. (2016). Synthesis and Characterization of Nanocrystalline Micro-Mesoporous ZSM5/MCM-41 Composite Zeolite. Iraqi Journal of Chemical and Petroleum Engineering, 17(1), 71-82.

[13] Nieto, A., Colilla, M., Balas, F., \& ValletRegí, M. (2010). Surface electrochemistry of mesoporous silicas as a key factor in the design of tailored delivery devices. Langmuir, 26(7), 5038-5049.

[14] Gary-Bobo, M., Hocine, O., Brevet, D., Maynadier, M., Raehm, L., Richeter, S., ... \& Garcia, M. (2012). Cancer therapy improvement with mesoporous silica nanoparticles combining targeting, drug delivery and PDT. International journal of pharmaceutics, 423(2), 509-515.

[15] Achouri, D., Hornebecq, V., Piccerelle, P., Andrieu, V., \& Sergent, M. (2015). Selfassembled liquid crystalline nanoparticles as an ophthalmic drug delivery system. Part I: influence of process parameters on their preparation studied by experimental design. Drug development and industrial pharmacy, 41(1), 109-115.

[16] Monti, D., Egiziano, E., Burgalassi, S., Tampucci, S., Terreni, E., Tivegna, S., \& Chetoni, P. (2018). Influence of a Combination of Chemical Enhancers and Iontophoresis on In Vitro Transungual Permeation of Nystatin. AAPS PharmSciTech, 19(4), 1574-1581.

[17] Sakeer, K., Al-Zein, H., Hassan, I., Desai, S., \& Nokhodchi, A. (2010). Enhancement of dissolution of nystatin from buccoadhesive tablets containing various surfactants and a solid dispersion formulation. Archives of pharmacal research, 33(11), 1771-1779.

[18] Bassi, P., \& Kaur, G. (2015). Bioadhesive vaginal drug delivery of nystatin using a derivatized polymer: development and characterization. European Journal of Pharmaceutics and Biopharmaceutics, 96, 173-184.

[19] Zhao, D., Feng, J., Huo, Q., Melosh, N., Fredrickson, G. H., Chmelka, B. F., \& Stucky, G. D. (1998). Triblock copolymer syntheses of mesoporous silica with periodic 50 to $300 \quad$ angstrom pores. science, 279(5350), 548-552.

[20] Albayati, T. M., Alwan, G. M., \& Mahdy, O. S. (2017). High performance methyl orange capture on magnetic nanoporous MCM-41 prepared by incipient wetness impregnation method. Korean Journal of Chemical Engineering, 34(1), 259-265.

[21] Ahmadi, E., Dehghannejad, N., Hashemikia, S., Ghasemnejad, M., \& Tabebordbar, H. (2014). Synthesis and surface modification of mesoporous silica nanoparticles and its application as carriers for sustained drug delivery. Drug delivery, 21(3), 164-172.

[22] Lang, Y., Finn, D. P., Pandit, A., \& Walsh, P. J. (2012). Pharmacological activity of 
ibuprofen released from mesoporous silica. Journal of Materials Science: Materials in Medicine, 23(1), 73-80.

[23] Chopra, S., Patil, G. V., \& Motwani, S. K. (2007). Release modulating hydrophilic matrix systems of losartan potassium: Optimization of formulation using statistical experimental design. European journal of pharmaceutics and Biopharmaceutics, 66(1), 73-82.

[24] Chen, X. Y., Shang, Y. L., Li, Y. H., Wang, J. X., Maimouna, A. G., Li, Y. X., ... \& Pu, Y. (2015). Green preparation of uniform prednisolone nanoparticles using subcritical water. Chemical Engineering Journal, 263, 20-26.

[25] Gunduz, O., Yetmez, M., Sonmez, M., Georgescu, M., Alexandrescu, L., Ficai, A., ... \& Andronescu, E. (2015). Mesoporous materials used in medicine and environmental applications. Current topics in medicinal chemistry, 15(15), 1501-1515.

[26] Farjadian, F., Ahmadpour, P., Samani, S. M., \& Hosseini, M. (2015). Controlled size synthesis and application of nanosphere MCM-41 as potent adsorber of drugs: a novel approach to new antidote agent for intoxication. Microporous and Mesoporous Materials, 213, 30-39.

[27] Shah, P. V., \& Rajput, S. J. (2017). A comparative in vitro release study of raloxifene encapsulated ordered MCM-41 and MCM-48 nanoparticles: a dissolution kinetics study in simulated and biorelevant media. Journal of Drug Delivery Science and Technology, 41, 31-44.

[28] Tsai, F. C., Ma, N., Chiang, T. C., Tsai, L. C., Shi, J. J., Xia, Y., ... \& Chuang, F. S. (2014). Adsorptive removal of methyl orange from aqueous solution with crosslinking chitosan microspheres. Journal of Water Process Engineering, 1, 2-7.

[29] Lee, C. H., Lo, L. W., Mou, C. Y., \& Yang, C. S. (2008). Synthesis and characterization of positive-charge functionalized mesoporous silica nanoparticles for oral drug delivery of an anti-inflammatory drug. Advanced Functional Materials, 18(20), 3283-3292.

[30] Falahat, R. (2016). Tunable Nano-Delivery System for Cancer Treatment: A New Approach for Targeted Localized Drug Delivery. 


\title{
السليكا المساميَة MCM-41 مادة ناقلة لعلاج النستاتين لنظام تسليم الدواء
}

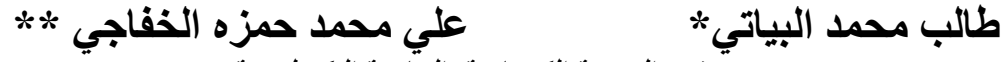

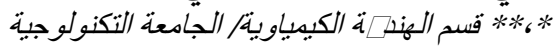

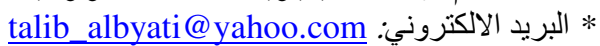 \\ alkafagae1986@yahoo.com البريد الالكتروني:
}

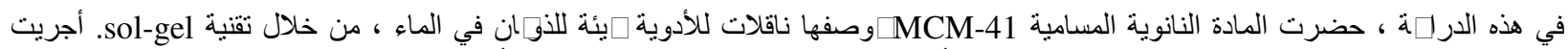

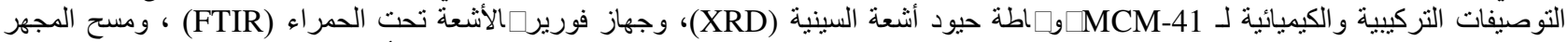

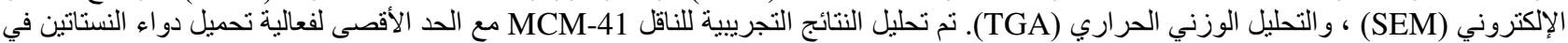

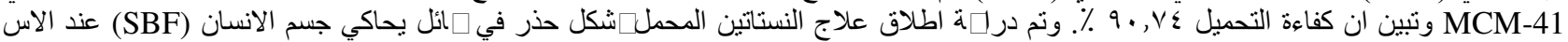

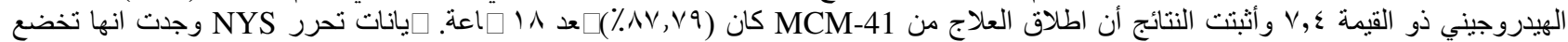

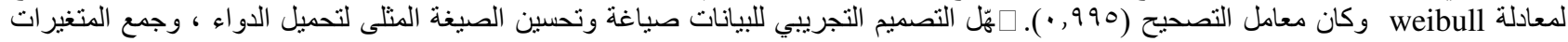

